\title{
PEMBERDAYAAN MASYARAKAT PUNDUNG, WUKIRSARI, IMOGIRI, BANTUL PROGRAM INOVASI BARU TEH CELUP WEDANG UWUH
}

\author{
Oleh: \\ Septian Emma DJ dan mahasiswa KKN Reguler 63 devisi II.A.2 \\ Universitas Ahmad Dahlan Yogyakarta
}

\section{Ringkasan}

Salah satu permasalahan yang ada di masyarakat Pundung, desa Wukirsari, kecamatan Imogiri, kabupaten Bantul, Yogyakarta yaitu banyaknya pengrajin wedang uwuh namun masih tedapat berbagai macam permasalahan yang harus ditangani, diantaranya belum terdapatnya kelompok usaha pengrajin wedang uwuh, belum memiliki ijin P-IRT, serta kemasan yang masih sangat sederhana sehingga program KKN UAD difokuskan untuk mengatasi permasalahan tersebut. Program ini bertujuan memberdayakan masyarakat Pundung dalam program inovasi baru teh celup wedang uwuh agar dapat meningkatkan harga jual produk wedang uwuh yang dapat meningkatkan taraf kehidupan pengrajin wedang uwuh. Metode pelaksanaan program KKN meliputi: pendidikan masyarakat, difusi teknologi dan praktek langsung. Dampak dari kegiatan KKN ini adalah: 1) Meningkatnya taraf kehidupan masyarakat Desa Wukirsari melalui pemberdayaan masyarakat untuk industri rumah tangga 2) Terciptanya rumah produksi dan kelompok produksi teh celup wedang uwuh yang berkompeten, 3) Peningkatan pengetahuan dan ketrampilan kelompok produksi teh celup wedang uwuh.

Kata kunci : Pemberdayaan, Pundung, Wedang Uwuh.

\begin{abstract}
One of the problems that exist in the community Pundung, the village of Wukirsari, Imogiri, Bantul Regency, Yogyakarta, that many craftsmen of wedang uwuh but have many problems to be completed, the problems are a group of wedang uwuh production don't have, the other craftsmen don't have permission P-IRT, as well as the packaging is still a very simple program so that KKN $U A D$ focuse to completed that problems. This program aims at empowering communities Pundung in new innovation program teabag wedang uwuh in order to increase the selling price of a product that can improve the level of life craftsman wedang uwuh. The method of implementation of the program of KKN include: community education, diffusion of technology and practice. The impact of the activities of the KKN are: 1) Community empowerment Wukirsari Village to industrial households 2) The creation of production and production group teabag wedang uwuh competent, 3) Increased knowledge and skills Group production of teabag wedang uwuh.
\end{abstract}

Keywords: Empowerment, Pundung, Wedang Uwuh.

\section{A. PENDAHULUAN}

Desa Wukirsari merupakan salah satu desa di kecamatan Imogiri yang memiliki pengrajin wedang uwuh terbanyak selain desa Girirejo. Desa Wukirsari memiliki luas wilayah yaitu 15,39 $\mathrm{km}^{2}$ atau sekitar 3,04\% dari luas Kabupaten Bantul terdiri dari 15 pedukuhan yaitu Tilaman, Karangkulon, Giriloyo, Nagasari I, Nagasari II, Kedungbuweng, Cengkehan, Pundung, Sindet, Karangtalun, Singosaren, Jatirejo, Bendo, Dengkeng, Karangasem. Berdasarkan bidang sosial ekonomi profil masyarakat Desa Wukirsari sebagian bekerja sebagai petani. Dari data monografi Kecamatan tercatat 13.431 orang atau $23,83 \%$ penduduk Kecamatan Imogiri bekerja di sektor pertanian 
(Profil Kecamatan Imogiri, 2014). Menjadi pengrajin wedang uwuh merupakan salah satu cara yang dilakukan masyarakat wukirsari untuk meningkatkan penghasilan mereka.

Dusun Pundung di desa wukirsari merupakan salah satu desa yang memiliki potensi dalam mengembangkan inovasi teh celup wedang uwuh karena di dusun Pundung terdapat banyak pengrajin wedang uwuh namun, hanya satu produsen yang membuat wedang uwuh dengan menggunakan sediaan teh celup.Wedang uwuh merupakan minuman khas dari Imogiri. Melihat perkembangan daerah Imogiri yang terus berkembang menjadi daerah wisata, maka minuman wedang uwuh menjadi suatu daya tarik tersendiri bagi wisatawan.

Wedang uwuh terdiri dari berbagai komponen herbal diantaranya rimpang jahe, daun manisjangan, daun pala, daun cengkeh, cengkeh, daun secang dan gula batu (Gusti Grehenson, 2008). Masing-masing komponen memiliki manfaat tersendiri. Rimpang jahe misalnya memiliki beranekaragam manfaat diantaranya menambah nafsu makan, memperkuat lambung, pelancar sirkulasi darah, penurun kolestrol, antimuntah, antiradang, dan memperbaiki pencernaan (Trilaksani, W.2003), daun pala memberikan efek rileksasi sehingga tidur lebih nyenyak. Selain membuat inovasi dalam bentuk kemasan teh celup wedang uwuh, inovator juga menambahkan 2 komponen herbal dalam produk wedang uwuh diantaranya seledri yang bermanfaat menurunkan tekanan darah serta daun sirsak bermanfaat untuk menurunkan kadar gula darah (Purwatresna, 2012).

Terdapat lebih dari 10 pengrajin wedang uwuh di Dusun Pundung baik dari skala kecil maupun skala besar. Namun, belum terdapatnya kelompok usaha pengrajin wedang uwuh di Desa Wukirsari merupakan salah satu faktor yang menghambat berkembangnya potensi lokal wedang uwuh, selain itu sebagian besar produk wedang uwuh di dusun Pundung belum memiliki ijin P-IRT (Pangan Industri Rumah Tangga) sehingga kualitas produk wedang uwuh masih diragukan. Permasalahan lain yang timbul yaitu sediaan wedang uwuh yang diproduksi jika dilihat dari sisi kemasan masih sangat sederhana, hanya berupa komponen kering yang dibungkus plastik, sehingga kemasan tersebut terlihat kurang menarik, penyajiannya agak merepotkan dan tidak tahan disimpan dalam waktu yang cukup lama, hal tersebut menyebabkan nilai ekonomi dari wedang uwuh kemasan plastik ini masih rendah.. Oleh karena itu diperlukan inovasi baru untuk menyajikan wedang uwuh dalam bentuk yang lebih menarik, awet dan mudah disajikan (Kristianingrum, et al., 2009).

\section{B. METODE PELAKSANAAN}

Untuk mencapai tujuan yang diharapkan, program KKN di Dusun Pundung dilakukan kegiatan pemberdayaan masyarakat melalui pendidikan masyarakat, difusi ilmu pengetahuan dan teknologi dan praktek langsung. Ringkasan metode pelaksanaan beserta jam kerja efektif mahasiswa (JKEM) tersaji pada table I. 
Diterbitkan oleh Lembaga Pengabdian kepada Masyarakat

Universitas Ahmad Dahlan Yogyakarta

Tabel I. Metode, Kegiatan, JKEM dan keterlibatan mahasiswa

\begin{tabular}{|c|c|c|c|c|}
\hline No & Metode & Kegiatan & JKEM & $\begin{array}{l}\text { Jumlah } \\
\text { Mahasiswa } \\
\text { yang } \\
\text { Terlibat }\end{array}$ \\
\hline \multirow[t]{3}{*}{1} & \multirow[t]{3}{*}{$\begin{array}{l}\text { Pendidikan } \\
\text { masyarakat }\end{array}$} & $\begin{array}{l}\text { Menyelenggarakan Sosialisai dan } \\
\text { Koordinasi Program } \\
\text { Pemberdayaan Masyarakat. }\end{array}$ & 1x150 Menit & 8 \\
\hline & & Pelatihan Pengurusan Ijin P-IRT & 1x800 Menit & 8 \\
\hline & & $\begin{array}{l}\text { Pembentukan Kader Promotor } \\
\text { Kesehatan care for teen }\end{array}$ & 1x150 Menit & 8 \\
\hline \multirow[t]{6}{*}{2} & \multirow[t]{6}{*}{ Difusi iptek } & $\begin{array}{l}\text { Menyelenggarakan Pelatihan } \\
\text { Teknik Budidaya Tanaman Herbal } \\
\text { Menggunakan Sistem Hidroponik } \\
\text { dengan Memanfaatkan Limbah } \\
\text { Lingkungan. }\end{array}$ & $4 x 200$ Menit & 8 \\
\hline & & $\begin{array}{l}\text { Menyelenggarakan Pelatihan } \\
\text { Pengolahan Bahan Baku Pasca } \\
\text { Panen }\end{array}$ & 2x200 Menit & 8 \\
\hline & & $\begin{array}{l}\text { Menyelenggarakan Pelatihan } \\
\text { Pengembangan Formulasi Produk } \\
\text { Wedang Uwuh }\end{array}$ & $\begin{array}{ll}2 \times 200 & \text { Menit } \\
\text { dan } & 2 \times 150 \\
\text { Menit } & \end{array}$ & 8 \\
\hline & & $\begin{array}{l}\text { Menyelenggarakan Pelatihan } \\
\text { Pengembangan Sediaan Produk Teh } \\
\text { Celup Wedang Uwuh }\end{array}$ & 2x200 Menit & 8 \\
\hline & & $\begin{array}{l}\text { Pelatihan Teknik Desain Kemasan } \\
\text { Wedang Uwuh dan product } \\
\text { knowledge }\end{array}$ & $2 \times 200$ Menit & \\
\hline & & Pelatihan Strategi Marketing & $\begin{array}{ll}\text { 2x150 } & \text { Menit } \\
\text { dan } & 1 \times 200 \\
\text { Menit } & \\
\end{array}$ & 8 \\
\hline \multirow[t]{5}{*}{3} & \multirow[t]{5}{*}{ Praktek } & $\begin{array}{l}\text { Pendampingan Pembuatan Kebun } \\
\text { Hidroponik dan Pengolahan Bahan } \\
\text { Baku Wedang Uwuh Pasca Panen }\end{array}$ & $4 \times 50$ Menit & 8 \\
\hline & & Pendampingan Uji Kualitas Air & $1 \times 50$ Menit & 8 \\
\hline & & $\begin{array}{l}\text { Pendampingan Pengurusan Ijin P- } \\
\text { IRT }\end{array}$ & 2x50 Menit & 8 \\
\hline & & $\begin{array}{l}\text { Pendampingan Persiapan dan } \\
\text { Pembuatan Rumah Produksi Teh } \\
\text { Celup Wedang Uwuh }\end{array}$ & 1x50 Menit & 8 \\
\hline & & $\begin{array}{l}\text { Peresmian Rumah Produksi Teh } \\
\text { Celup Wedang Uwuh }\end{array}$ & 2x150 Menit & 8 \\
\hline
\end{tabular}




\section{HASIL, PEMBAHASAN DAN DAMPAK}

\section{Profil Desa}

Desa Wukirsari merupakan salah satu desa yang ada di kecamatan Imogiri, kabupaten Bantul. Wilayah kelurahan Wukirsari ini mempunyai batas wilayah diantaranya sebelah utara berbatasan dengan kecamatan Pleret, selatan berbatasan dengan desa girirejo dan desa mangunan, barat berbatasan dengan desa Trimulyo dan timur berbatasan dengan Kecamatan Dlingo.

Luas wilayah Desa Wukirsari yaitu 15,39 km2 atau sekitar 3,04\% dari luas Kabupaten Bantul. Desa Wukirsari terdiri dari 15 pedukuhan yaitu Tilaman, Karangkulon, Giriloyo, Nagasari I, Nagasari II, Kedungbuweng, Cengkehan, Pundung, Sindet, Karangtalun, Singosaren, Jatirejo, Bendo, Dengkeng, Karangasem. Gambar 1 merupakan Peta Administratif Desa Wukirsari.

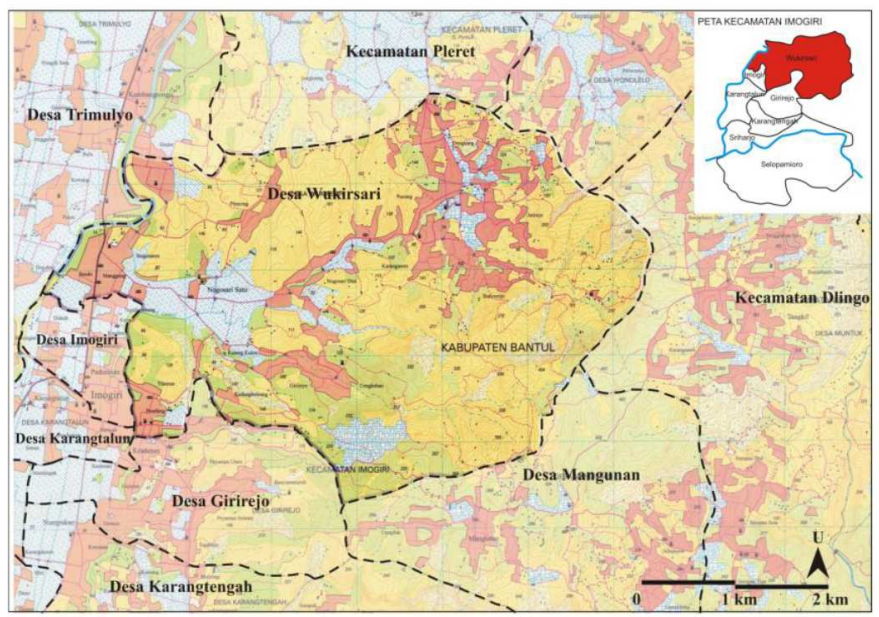

Gambar 1. Peta Lokasi Desa Wukirsari

(Sumber: Peta Rupabumi Imogiri Lembar 1408-222)

Jumlah Kepala Keluarga (KK) Desa Wukirsari berdasarkan profil desa tahun 2017 yaitu 5.428 KK dengan total penduduk sebanyak 17.445 jiwa. Dari jumlah ini, sebanyak 35,8\% merupakan usia produktif (17-50 tahun), sisanya sebanyak 32,3\% merupakan usia sekolah dan 31,9\% merupakan kaum lanjut usia.

Berdasarkan bidang sosial ekonomi profil Desa mayoritas masyarakat Desa Wukirsari bekerja diseketor pertanian.. 
Diterbitkan oleh Lembaga Pengabdian kepada Masyarakat

Universitas Ahmad Dahlan Yogyakarta

\section{Gambaran Pelaksanaan}

Gambar aktivitas mahasiswa KKN UAD Reguler 63 dan masyarakat dusun Pundung dalam program gambar 2

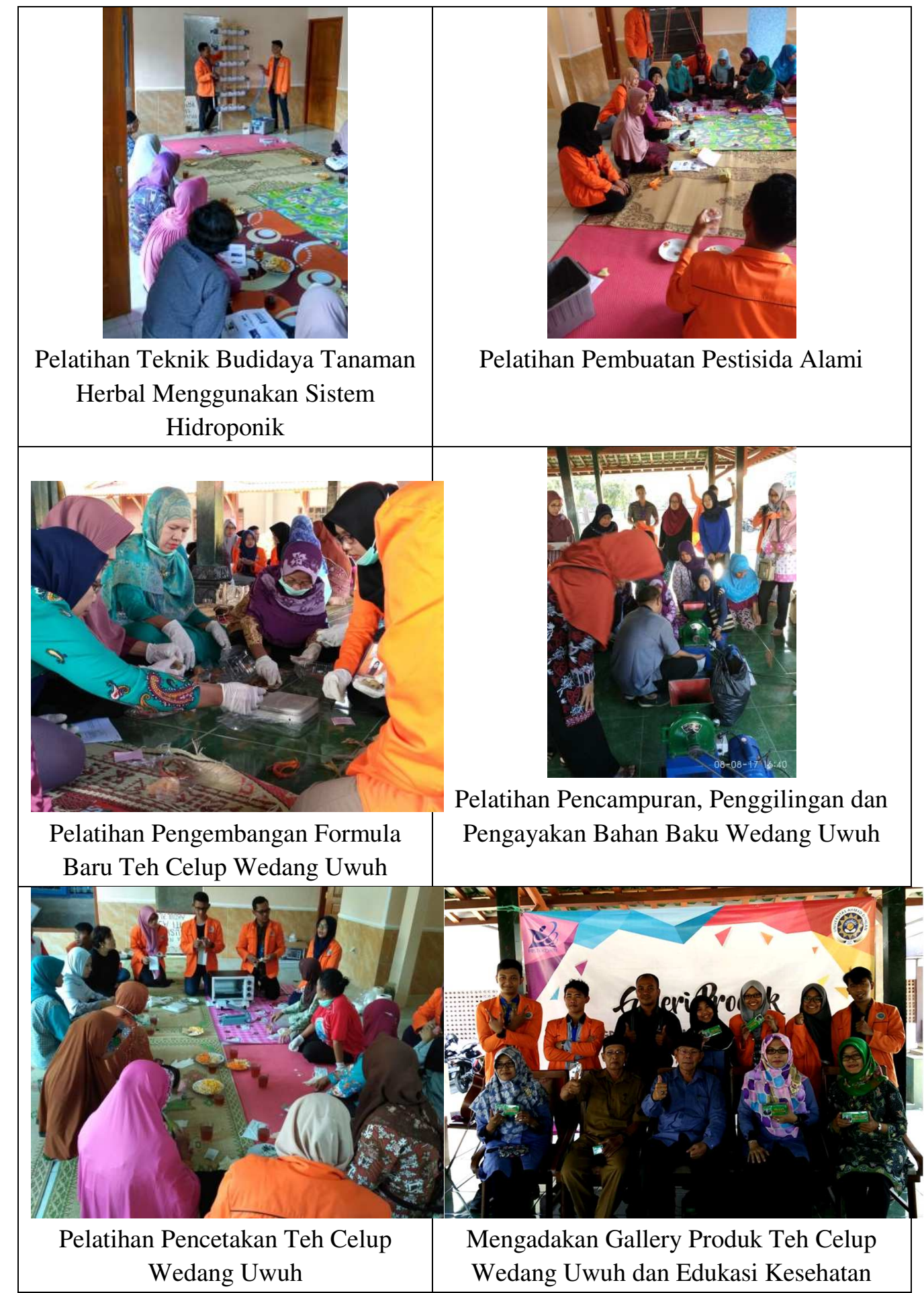

Gambar 2. Aktivitas mahasiswa KKN UAD dan masyarakat Pundung dalam program Inovasi Baru Teh Celup Wedang Uwuh 
Dari gambar 2 terlihat berbagai macam program KKN di Pundung dapat terlaksana dengan melibatkan partisipasi masyarakat yang cukup tinggi, dengan kata lain dapat memperdayakan masyarakat dalam program-program yang telah direncanakan. Dampak dari kegiatan KKN ini diantaranya: 1) Meningkatnya taraf kehidupan masyarakat Desa Wukirsari melalui pemberdayaan masyarakat untuk industri rumah tangga 2) Terciptanya rumah produksi dan kelompok produksi teh celup wedang uwuh yang berkompeten, 3) Peningkatan pengetahuan dan ketrampilan kelompok produksi teh celup wedang uwuh.

\section{KESIMPULAN}

Program KKN UAD dalam memberdayakan masyarakat Pundung terhadap inovasi baru teh celup wedang uwuh berjalan dengan baik dan dapat memberikan manfaat terhadap masyarakat Pundung.

\section{DAFTAR PUSTAKA}

Gusti Grehenson.2008.Wedang Uwuh.Yogyakarta: Humas UGM.

Kristianingrum,S.2009. Pembuatan Wedang Uwuh Celup. Kimia FMIPA Universitas Negri Yogyakarta.Yogyakarta.

Purwatresna,E.2012.Aktivitas Antidiabetes Ekstrak Air dan Etanol Daun Sirsak Secara In Vitro melalui Inhibisi Enzim A-Glukosidase.Institut Pertanian Bogor. Bogor.

Trilaksani,W.2003.Antioksidan: Jenis,Sumber, Mekanisme Kerja dan Peran Terhadap Kesehatan.Term-Paper Graduate Program S3.Bogor: IPB. 